\title{
Measuring perceived social presence in distributed learning groups
}

Citation for published version (APA):

Kreijns, K., Kirschner, P. A., Jochems, W., \& Van Buuren, H. (2011). Measuring perceived social presence in distributed learning groups. Education and Information Technologies, 16(4), 365-381.

https://doi.org/10.1007/s10639-010-9135-7

DOI:

10.1007/s10639-010-9135-7

Document status and date:

Published: 01/12/2011

Document Version:

Peer reviewed version

Document license:

CC BY-NC-SA

Please check the document version of this publication:

- A submitted manuscript is the version of the article upon submission and before peer-review. There can be important differences between the submitted version and the official published version of record. People interested in the research are advised to contact the author for the final version of the publication, or visit the DOI to the publisher's website.

- The final author version and the galley proof are versions of the publication after peer review.

- The final published version features the final layout of the paper including the volume, issue and page numbers.

Link to publication

\section{General rights}

Copyright and moral rights for the publications made accessible in the public portal are retained by the authors and/or other copyright owners and it is a condition of accessing publications that users recognise and abide by the legal requirements associated with these rights.

- Users may download and print one copy of any publication from the public portal for the purpose of private study or research.

- You may not further distribute the material or use it for any profit-making activity or commercial gain

- You may freely distribute the URL identifying the publication in the public portal.

If the publication is distributed under the terms of Article 25fa of the Dutch Copyright Act, indicated by the "Taverne" license above, please follow below link for the End User Agreement:

https://www.ou.nl/taverne-agreement

Take down policy

If you believe that this document breaches copyright please contact us at:

pure-support@ou.nl

providing details and we will investigate your claim.

Downloaded from https://research.ou.nl/ on date: 26 Apr. 2023 


\section{Editorial Manager(tm) for Education and Information Technologies Manuscript Draft}

Manuscript Number: EAIT-183R1

Title: Measuring Perceived Social Presence in Distributed Learning Groups

Article Type: Manuscript

Keywords: Social Presence; Social Presence Scale; Sociability; Social Affordances

Corresponding Author: Karel Kreijns,

Corresponding Author's Institution:

First Author: Karel Kreijns

Order of Authors: Karel Kreijns; Paul A. Kirschner, Ph.D; Wim Jochems, Ph.D; Hans van Buuren, Ph.D 
COMMENTS FOR THE AUTHOR:

Reviewer \#1: Interesting and relevant topic Well written, however structure tends to be 'bitty' i.e. to many small sections. The flow of the litertaure review may be better if the number of sections were reduced.

Authors: We have corrected this by reducing the number of sections and grouping them thematically.

Reviewer \#1: Could also use some more recent/current references latest one is 2003, 7 years old.

Authors: We added the following references

Cobb, S. C. (2009). Social presence and online learning: A current view from a research perspective. Journal of Interactive Online Learning, 8(3), 241254.

Hills, A. (2005). Social presence and communication quality in videoconferencing. Unpublished bachelor dissertation, University of Otago, New Zealand

Koh, J., Kim, Y.-G., Butler, B., Bock, G.-W. (2007). Encouraging participation in virtual communities. Communications of the ACM. 50(2), 69-73.

Lin, G.-Y. (2004, October 19-23). Social Presence Questionnaire of OnLine Collaborative Learning: Development and Validity. Paper presented at the 27th Association for Educational Communications and Technology (AECT) Covention. Chicago, IL.

Liu, S. Y., Gomez, J., \& Yen, C-J., (2009). Community college online course retention and final grade: Predictablility of social presence. Journal of Interactive Online Learning, 8(2), 165-182.

Lowenthal, P. R. (2010). The evolution and influence of social presence theory on online learning. In T. T. Kidd (Ed.), Online Education and Adult Learning: New Frontiers for Teaching Practices (pp. 124-134). Hershey, PA: IGI Global.

Shen, K. N., Khalifa, M., \& Yu, A Y. (2006, August 4-6). Supporting social interaction in virtual communities: Role of social presence. Paper presented at the 12th Americas conference on Information systems. Acapulco, Mexico.

This, of course, resulted in slight additions to the text and, because of these new references the content of some sections had to be reshuffled.

Reviewer \#1: Empirical work is well executed and thorough.

Authors: Thank you.

Reviewer \#1: Redo structure and include more up to date references.

Authors: Done. 
Reviewer \#2: Review paper No: EAIT-183

Title: 'Measuring Perceived Social Presence in Distributed Learning Groups'

This paper address the construction and validation of a self-reporting (Dutchlanguage) Social Presence Scale to determine perceived social presence in distributed learning groups using computer-supported collaborative learning environments. The concept of social presence is important because it affects participation and social interaction, both necessary for effective collaboration and knowledge construction. Despite this fact, the contribution of this paper is not clear. Specifically, most of the details on the development of the proposed instrument are presented in the following two other papers:

1) WIM JOCHEMS and KAREL KREIJNS (2006). Measuring Social Aspects of Distributed Learning Groups. European Educational Research Journal, Volume 5, Number 2, 2006 DOI: 10.2304/eerj.2006.5.2.110

2) Karel Kreijns, Paul A. Kirschner, Wim Jochems, and Hans van Buuren (2004). Measuring perceived quality of social space in distributed learning groups. Computers in Human Behavior, 20 (2004) 607-632

Authors: The previous two publications only refer to the social presence scale and its items in order to show its relationship with the two other scales (social space scale \& sociability scale). However, these publications never discussed social presence theory in depth and the problems with the measures used. The present article corrects this and, therefore, in our opinion contributes to the body of knowledge about social presence in an educational context. This has been made clear in the article.

Reviewer \#2: The composition of the scale, the experiment and the methodology followed as well as the limitations of the proposed instrument are elaborated in detail in those two papers. In fact, one can see the Table 1 (Page 5 of the submitted paper) presented as Table II in the first paper of the above (see page 115). In addition, part of Table 2 (its' last four columns; on page 8 of the submitted paper) is presented on page 118 of the aforementioned paper (see 3rd column of Table V; page 118). Furthermore, all items of Table 3 (see pages 8-9 of the submitted paper) are presented in Tables III, II and I in the previously mentioned paper (see pages: 115 and 114 correspondingly). Based on the above, there does not seem to exist sufficient new information or justification to warrant publication in the EAIT journal.

Authors: Indeed, previous two publications show the social presence scale in a table but the information about the scale itself was brief. This article elaborates social presence theory and presents other definitions and conceptualizations of social presence. Moreover the problems of existing scales are discussed which gives context to our decision to develop an alternative social presence scale. The two other publications miss this information. 


\title{
Measuring Perceived Social Presence in Distributed Learning Groups
}

\author{
Karel Kreijns $^{1,2}$, Paul A. Kirschner ${ }^{1}$, Wim Jochems ${ }^{3}$, and Hans van Buuren ${ }^{1}$ \\ ${ }^{1}$ Open Universiteit Nederland, Heerlen, The Netherlands \\ ${ }^{2}$ Fontys University of Applied Sciences, Eindhoven, The Netherlands \\ ${ }^{3}$ Eindhoven School of Education, Eindhoven, The Netherlands
}

Correspondence concerning this paper should be addressed to Karel Kreijns, Open Universiteit Nederland, Ruud de Moor Center for Teacher Professionalization, P.O. Box 2960, 6401 DL Heerlen, The Netherlands. E-mail: karel.kreijns@ou.nl

\begin{abstract}
Social presence - the degree to which 'the other' in a communication appears to be a 'real' person has captured the attention of those dealing with learning in groups through computer-supported collaborative learning environments. The concept is important because it affects participation and social interaction, both necessary for effective collaboration and knowledge construction. This article reports on the construction and validation of a self-reporting (Dutch-language) Social Presence Scale to determine perceived social presence in distributed learning groups using computer-supported collaborative learning environments. The result is a onedimensional scale consisting of five items with an internal consistency of .81. We used a nomological network of similar constructs for further validation. The findings suggest that the Social Presence Scale has potential to be useful as a measure for social presence.
\end{abstract}

Keywords Social Presence, Social Presence Scale, Sociability, Social Affordances

\section{Introduction}

In synchronous and asynchronous learning groups social presence (Short, Williams, \& Christie, 1976) is an important determinant for both participation (Koh, Kim, Butler, \& Bock, 2007; Shen, Khalifa, \& Yu, 2006; Stacey, 2000) and social interaction (Cobb, 2009; Garrison, 1997; Garrison \& Anderson, 2003; Lowenthal, 2010; Stacey, 2002; Swan, 2002; Tu \& McIsaac, 2002). Inspired by telepresence research (Lombard \& Ditton, 1997) we define social presence as the degree of illusion that others appear to be a 'real' physical persons in either an immediate (i.e., real time/synchronous) or a delayed (i.e., time-deferred/asynchronous) communication episode. If "social presence is low, the foundation of social learning, social interaction, does not occur" (Tu, 2000a, p. 30; cf., Garramone, Harris, \& Anderson, 1986). Tu (2000a), linking social learning theory to social presence, took this a step further when he asserted that social presence "is required to enhance and foster online social interaction, which is the major vehicle of social learning" (p. 27). And, since social presence is so important for maintaining a high degree of online social interaction, it "is a significant predictor of course retention and final grade in the community college online environment" (Liu, Gomez, and Yen, 2009, p. 165).

Social interaction has long been seen as a prerequisite for collaborative learning and knowledge construction (Hiltz, 1994; Kearsley, 1995; Slavin, 1995). Garrison (1993) suggested that it promotes explanation and helps develop critical perspectives on a problem, leading to true meaning. Soller, Lesgold, Linton, and Goodman (1999) saw it as instrumental in making peer interaction more effective since students "learning effectively in groups encourage each other to ask questions, explain and justify their opinions, articulate their reasoning, and elaborate and reflect upon their knowledge" (p. 116). Johnson, Johnson, and Stanne (1985) emphasized that "the cognitive processes most necessary for deeper level understanding and the implanting of information into memory, such as elaboration and metacognition, occur only through dialogue and interaction with other people" (p. 675).

In addition, social interaction is also important for socio-emotional and social processes related to group formation and group dynamics affecting affiliation, impression formation, developing affective relationships, and building social cohesiveness and community. Only when groups attain strong social cohesiveness, trust, belonging, and a sense of community can they effectively accomplish their learning tasks (Gunawardena, 1995; Gunawardena \& Zittle, 1997; Jacques, 1992; Kreijns, Kirschner, \& Jochems, 2003).

This study is the third in a series of experiments to develop instruments for determining how users of CSCL environments experience those environments. The first (Kreijns, Kirschner, Jochems, \& Van Buuren, 
2004) produced an instrument for determining social space and the second (Kreijns, Kirschner, Jochems, \& Van Buuren, 2007) one for determining sociability. This study has resulted in an instrument for determining social presence.

\section{Short, Williams, and Christie's Social Presence Theory}

Short, Williams, and Christie's (1976) social presence theory explains the interpersonal effects occuring between two interlocutors when communicating, regardless of the medium. They characterized different media in terms of their potential to communicate verbal and non-verbal cues conveying socio-emotional information such that the other is perceived as 'physically' present. Non-verbal cues can be visual (e.g., facial expression, posture), auditory (e.g., voice volume, inflection), tactile (e.g., touching, shaking hands), and olfactory (e.g., smells). Short et al. defined social presence as the "degree of salience of the other person in the interaction and the consequent salience of the interpersonal relationships [that] varies between different media, [affecting] the nature of the interaction and [interacting] with the purpose of [influencing] the medium chosen by the individual who wishes to communicate" (p. 65). In their initial view, they held that the physical and technological characteristics of a medium were solely responsible for its degree of social presence; an objective quality of the communication medium. They eventually relaxed their view to include subjective qualities of the medium (Walther \& Burgoon, 1992).

Social presence theory has often been used to rank telecommunication media according their degree of social presence (i.e., face-to-face > video-conferencing $>$ audio). According to the theory, media higher in social presence are more appropriate for carrying-out interpersonal tasks (Rice, 1993; Steinfield, 1986). In other words, developing and maintaining mutual trust in tasks that require conflict-resolution or negotiation require communication media which are high in social presence because these media are more effective for trust building and, consequently, social influence (Fulk, Schmitz, \& Steinfield, 1990). It hypothesizes that mediachoice can be predicted such that "users of any given communications medium are in some sense aware of the degree of Social Presence of the medium and tend to avoid using the medium for certain types of interactions; specifically, interactions requiring a higher degree of Social Presence than they perceive the medium to have" (Short et al, 1976, p. 65).

Finally, Short et al (1976) related two other social psychological concepts to social presence, namely intimacy (Argyle \& Dean, 1965) and immediacy (Wiener \& Mehrabian, 1968). According to Argyle and Dean's equilibrium theory, communicating participants reach an optimal level of intimacy where conflicting approach and avoidance forces are in equilibrium. Immediacy, is a "measure of the psychological distance which a communicator puts between himself [sic] and the object of his communication, his addressee or his communication...negative affect, low evaluation and non-preference for any of these things are associated with non-immediacy in communications" (Short et al, p. 72). According to Gunawardena (1995), immediacy enhances social presence.

\section{Towards an Alternative Measure of Social Presence}

Though social presence theory is both useful and attractive, it does have a number of problems. Lowenthal (2010), for example, pointed out that "despite its intuitive appeal, researchers and practitioners alike often define and conceptualize this popular construct differently. In fact, it is often hard to distinguish between whether someone is talking about social interaction, immediacy, intimacy, emotion, and/or connectedness when they talk about social presence" (p. 125). A number of these problems are discussed in the following subsections.

\subsection{Technological versus social determism}

Social presence theory is a prime example of technological determinism; the idea that it is a society's technology that drives the development of its social structure and cultural values. In the view of Short et al. (1976), it is the technology that determines the perception of social presence. In contrast, others (e.g., Gunawardena, 1995; Tu, $2002 \mathrm{~b}$ ) argued that in the perception of social presence, media attributes are irrelevant. The social factors are what are important. These two extremes illustrate what Spears, Postmes, Wolbert, Lea, and Rogers (2000) called the 'technological vs. social determinism' controversy. In their eyes, 'simple' theories over-generalize ICTs' social effects by assuming "that ICTs' effects are due to characteristics of the technology or that these are constructed by social factors" (p. 8). They found that "the diversity of social effects precludes that technology is singularly good or bad, and that technology determines the social effects. Conversely, social determinism [ - the idea that social interactions and constructs alone determine individual behavior - ] cannot account for invariable technological effects: not every use of ICTs is as flexible as these theories claim. Moreover, social determinism often is relativistic, which restricts its power of prediction and practical use... a theory of the social effects of ICT must emphasize that the use and effect of the new technologies are co-determined by technological features 
(anonymity, isolation, and asynchrony) and social psychological factors (identities, social relations, and social practices)" (p. 8).

\subsection{Definitions and conceptualization of Social Presence}

Gunawardena (1995) adapted Short et al's (1976) definition. In her view, developing social presence is key to promoting collaborative learning and knowledge building and is a predictor of learner satisfaction (Gunawardena $\&$ Zittle, 1997). She concluded that "although CMC is described as a medium that is low in non-verbal cues and social context cues, participants in conferences create social presence by projecting their identities and building online communities" (p. 163). Garrison, Anderson, and Archer (2000) expanded this perspective defining social presence as "the ability of participants in a community of inquiry to project themselves socially and emotionally, as 'real' people (i.e., their full personality), through the medium of communication being used" (p. 94). They argued that it is important because it functions as "support for cognitive presence, indirectly facilitating the process of critical thinking carried on by the community of learners... and is a direct contributor to the success of the educational experience" (p. 89).

Tu (2000a, 2001, 2002a, 2002b, 2002c) used a variety of definitions of social presence, defining social presence as the degree "of person-to-person awareness, which occurs in a mediated environment" (2002b, p. 34) and "of feeling, perception and reaction of being connected on CMC to another intellectual entity" (2002c, p. 2). In his view, social presence is key to determining the social interaction in group learning, identifying three main variables contributing to social presence, namely:

1. Social context: constructed from the users' characteristics and their perceptions of a CMC environment.

2. Online communication: related to the attributes of the online language and its application.

3. Interactivity: active communication and learning activities that users engage in and the utility of the communication styles.

In agreement with Witmer (1997), Tu (2002a) suggested two other - privacy related - variables that could affect the degree of perceived social presence, namely:

4. System privacy: actual security of CMC technologies offered, including the likelihood that the system will allow unknown others to read, send, or resend messages.

5. Feelings of privacy: "perception of privacy psychologically, mentally, culturally, or conditionally rather than actual security" (p. 297).

\subsection{Measuring Perceived Social Presence}

Although a number of measures exists that purport to measure social presence, close examination of these instruments reveals that each also measures aspects of other constructs such as social climate, social interaction, cohesiveness, social space, and sociability. Also, some measures intended to measure social presence are used to measure other constructs such as social environment or attitude. We present some examples to illustrate this.

The dominant social presence measure was developed by Short et al (1976). They used four, 7-point semantic differential scales to measure the subjective degree of social presence: personal-impersonal, sensitiveinsensitive, warm-cold, and sociable-unsociable. The more personal, sensitive, warm, and sociable the medium is perceived to be, the higher social presence is. However, though their social presence theory is based on objective qualities of media, they based their measure on the subjective qualities of the media. While Walther (1992), questioned whether it is appropriate to determine the degree of social presence from such an objective perspective, we temper this conclusion since in the alternative perspective on social presence -which sees social presence as a psychological sensation- the measure could be valid. A different criticism is made by Tu (2002b) who argued that the four items used are too general to measure such a complicated concept and attacks the semantic differential technique as faulty since different respondents may ascribe different definitions and meanings to the adjectives used as semantic opposites.

Other social presence measures have been developed by Gunawardena (1995), Gunawardena and Zittle (1997) and Tu (2000b). Gunawardena developed her Social Presence Indicators which are 17, 5-point semantic differential scales which includes the four scales developed by Short et al. Alternatively, Gunawardena and Zittle developed a social presence measure which consists of 14, 5-point Likert-scale items (GZ Social Presence Scale). They contended that the Social Presence Indicators measure the intimacy dimension of social presence (Argyle \& Dean, 1965) while the GZ Social Presence Scale measures its immediacy (Wiener \& Mehrabian, 1968).

Tu (2000b) developed his Social Presence and Privacy Questionnaire (SPPQ) to assess five social presence dimensions for e-mail, bulletin board and real-time discussion, namely Social context, Online communication, Interactivity, System privacy, and Feeling of privacy. All items are 5-point Likert scale items, except for one system privacy item. 
A completely different approach is measuring social presence through the analysis of the content of the communications within the environment. Rourke, Anderson, Archer, and Garrison's (1999) three categories of social expressions (i.e., affective, interactive, cohesive), for example, are used by some as template for such a content analysis.

\subsection{Problems with Existing Social Presence Measures}

A first problem is that it is not unequivocal what the instruments actually measure. In other words: What do the available instruments actually measure? Do they only measure social presence or do they also measure other variables such as attitude, cohesiveness, climate, feelings towards CMC, privacy, degree of interpersonal interaction, and so forth? The problem here seems to be caused by the researchers themselves. Rourke and Anderson (2002), for example, were not consistent in their use of the term social climate. They also used the term 'social environment' and, when referring to the instrument for measuring 'social climate', used the term 'social presence'. Their definition of social presence is based on Garrison et al's (2000) and is, thus, different from Short et al's (1976). In addition, they measured 'social communication' by measuring perceived frequencies of 15 social expressions; Rourke et al (1999) used almost the same social expressions, but this time to measure 'social presence.'

According to Gunawardena (1995), her Social Presence Indicators measure student perception of CMC as a social medium although she defined social presence as "the degree to which a person is perceived as a 'real person' in mediated communication" (p. 151). Obviously, these two definitions are completely different. Also, Gunawardena and Zittle (1997) stated that their GZ Social Presence Scale measures the immediacy dimension of social presence. They, however, also stated that it measures the "perceived sense of 'online community', the degree of social comfort with CMC" (p. 14). According to Lowenthal (2010): "Gunawardena and Zittle as well as Tu focused primarily on studying user's attitude whereas Rourke et al. focused on studying user's behaviors" (p. 131-132).

A second problem is that while the effects of social presence or variables correlated to social presence are measured, they are interpreted as being equal to social presence. In other words; social presence per se is not measured. Tu (2000b), for example, used variables correlated to social presence. Though he stated that "many different variables are cited in the literature that may contribute to the degree of social presence: recipients, topics, privacy, task, social relationship, communication style" (p. 39), some of them are explicitly part his social presence measure.

A third problem is that some of the measures have not been adequately validated. According to Lin (2004) "[N]o reliability and validity assessments of the social presence instruments developed by Short et al in 1976 \& Gunawardena in 1995 are reported" (p. 588). He further pointed out that "for the instrument developed by Gunawardena \& Zittle in 1997, concurrent validity of the social presence scales was indicated by the strong and positive correlation with bipolar social indicators based on Short et al's instrument; however, the scale itself was not validated" (p. 588). In spite of this serious problem, researchers continue to use these instruments or their derivates (see for example, Cobb, 2009; Hills, 2005).

A fourth problem is that some measures are confined to certain media types. Henniger and Viswanathan (2004), for example, criticized Tu's SPPQ measure for exactly this reason. According to them, Tu's model of scial presence was only examined in a text-based environment, therefore, "this model offers interesting insights into factors influencing social presence; however its scope is very limited due to the restriction to text-based computer-mediated communication"(p. 370).

Finally, content analysis based upon the template provided by Rourke et al (1999) does not give a clear answer as to how to calculate scores from frequencies and how to aggregate the scores of each indicator to provide a single measure of the degree of social presence. First, the frequencies (e.g., the number of vocatives found) are not normalized prohibiting comparisons between samples. Second, it is unclear how to weigh each indicator score (e.g., the number of vocatives can be much, much larger than the number of expressions of humor).

To conclude, existing social presence scales measure varying aspects of an amorphous set of variables including social presence - to varying degrees. This is confounded by the fact that not all scales exhibit the necessary content or construct validity nor do their authors present data regarding internal reliability. This has led us to the conclusion that we ourselves must develop an unequivocal alternative social presence measure.

\section{An Alternative Social Presence Scale}

We developed a self-reporting Social Presence Scale (in Dutch) that measures the perceived degree of social presence in a CSCL environment. Construction of the items in the scale was inspired by telepresence research (e.g., Lombart \& Ditton, 1997) which focused on measuring the degree that individuals feel that they are transported from 'here to there' and that 'they are there' (i.e., the telepresence-effect). Their instruments try to 
capture the 'sensation' of telepresence as a psychological phenomenon without any 'side-effects' In this vein, we constructed a social presence measure capturing the psychological sensation associated with social presence. Table 1 depicts our (refined) Social Presence Scale. The next section will explain how this refinement was achieved and the meaning of the last three columns.

Table 1 The Social Presence Scale

\begin{tabular}{llccc}
\hline $\begin{array}{l}\text { No. } \\
\text { Item }\end{array}$ & Item & $M$ & $S D$ & $\begin{array}{l}\text { Factor } \\
\text { Social Presence }\end{array}$ \\
\hline 1 & $\begin{array}{l}\text { When I have real-time conversations in this CSCL environment, I } \\
\text { have my communication partner in my mind's eye }\end{array}$ & 2.15 & 1.17 & .80 \\
2 & $\begin{array}{l}\text { When I have asynchronous conversations in this CSCL environment, } 2.75 \\
\text { I also have my communication partner in my mind's eye }\end{array}$ & 1.16 & .70 \\
3 & $\begin{array}{l}\text { When I have real-time conversations in this CSCL environment, I } \\
\text { feel that I deal with very real persons and not with abstract } \\
\text { anonymous persons }\end{array}$ & 2.90 & 1.50 & .79 \\
& $\begin{array}{l}\text { When I have asynchronous conversations in this CSCL environment, 3.56 } \\
\text { I also feel that I deal with very real persons and not with abstract } \\
\text { anonymous persons } \\
\text { Real-time conversations in this CSCL environment can hardly be } \\
\text { distinguished from face-to-face conversations }\end{array}$ & 1.21 & .79 \\
5 & 1.01 & .69
\end{tabular}

Note. Judgments were made on 5-point Likert scales ( 1 = not applicable at all; 2 = rarely applicable; $3=$ moderately applicable $; 4$ = largely applicable $; 5=$ totally applicable $)$.

\section{Method}

\subsection{Participation}

Students in three distance education courses at the Open University of the Netherlands (OUNL) participated in the study. In the first course (environmental policy), 35 students ( 25 males, 10 females) from four higher education institutions participated: OUNL ( 8 males, 2 females), Maastricht University (MU; 3 males, 6 females), Twente University (TU; 7 males, 1 female), and Fontys University of Applied Sciences (Fontys; 7 males, 1 female). OUNL- and MU students were combined and assigned to one of five groups; four groups had 4 participants, the remaining group had 3 participants. All TU students were assigned to one group of 8 participants. Finally, Fontys students were assigned to one of two groups; both groups had 4 participants. All groups were required to write an environmental advisory report and made use of eRoom ${ }^{\circledR}$ version 4.0 to do this. In the second course (on statistics), 38 adult undergraduates (all OUNL; 6 male, 32 female) were randomly assigned to one of seven groups consisting of 5 or 6 members each. Among these students, 2 female students were non-starters (i.e., they did not participate from the very beginning of the course). During the course, 10 students ( 2 males, 8 females) dropped out. Consequently, group sizes were decreased; four groups ended up with 3 participants, one group had 4 and the remaining two groups had 5. All groups had to study the same study-material and had to produce a concept research paper, making use of Studynet, the CSCL environment of the OUNL, which makes use of newsgroups for asynchronous communication and Microsoft ${ }^{\circledR}$ Netmeeting ${ }^{\mathrm{TM}}$ for synchronous communication. Use of telephone and e-mail were prohibited.

One hundred thirteen adult undergraduates (all OUNL; 24 male, 79 female) were enrolled in a third course (also on statistics). Students were randomly assigned to one of eight 'slow' groups, one of eight 'fast' groups, or one of two 'free' groups (in total 18 groups). Slow and free groups had approximately twice the time allotted to fast groups to complete the course (10 months and 6 months respectively). Collaboration was compulsory for the slow and fast groups, and voluntary for the free groups. Half of the slow groups and half of the fast groups had 4 members; the remaining slow and fast groups had 8 . The free groups had 5 and 12 participants. Among them, 6 female students were non-starters. During the course 14 students dropped out (4 males, 10 females) and 18 students moved to another group. Consequently, groups changed in composition and size. All groups had to study questionnaire use, moderation analysis with ANOVA, and regression analysis methods. Students had to use the same environment as the second course.

\subsection{Procedure}

Course 1 lasted 14 weeks. In that period, there were three face-to-face meetings, namely a kick-off meeting, an evaluation meeting halfway through the course, and a closing meeting. Immediately after the second face-to-face meeting, - in addition to the Social Presence Scale - a Social Space Scale, a Sociability Scale and all other scales 
discussed in the next section were administered electronically (using Dipolar Professional Quest ${ }^{\mathrm{TM}}$ software, release 2.2). From the 35 students, 11 (31.4\%) responded to the questionnaire of which 9 (25.7\%) responded to all items. All respondents were either OUNL- or MU students. Although response was low, we had agreed with those responsible for the course that students were to be asked only once to fill in the questionnaire.

The second course lasted 18 weeks in which three face-to-face meetings were organized. The same electronic questionnaire was launched. From the 26 students that actually participated (38 minus non-starters and dropouts) 18 (69.2\%) responded.

The third course had a variable length. Slow and free groups had 10 months to complete the course while fast groups had 6. At the time the questionnaire was launched, slow and free groups were still studying while the fast groups had already completed the course. From the 93 students that still participated (113 minus non-starters and dropouts), 50 (53.8\%) responded. Two students who dropped out also returned the questionnaire. The total number of respondents is therefore, 52. In more detail: from the 29 students in the fast groups, 20 (69.0\%) responded; from the 41 students in the slow groups, 20 (48.8\%) responded plus 1 drop-out. From the 23 students in the free groups, 10 (43.5\%) responded plus 1 drop-out.

\subsection{Instrumentation}

The validation process used six measures dealing with constructs related to the social presence construct, namely:

1. Social Space Scale (Kreijns, Kirschner, Jochems, \& Van Buuren, 2004)

2. Sociability Scale (Kreijns, Kirschner, Jochems, \& Van Buuren, 2007)

3. Social Presence Indicators (Gunawardena, 1995)

4. Social Presence Scale (Gunawardena \& Zittle, 1997)

5. Work-Group Cohesiveness Index (Price \& Mueller, 1986)

6. Group Atmosphere Scale (Fiedler, 1962, 1967)

The (Dutch language) Social Space Scale measures the degree of perceived quality of a social space existing in a distributed learning group, synchronous or asynchronous. Kreijns, Kirschner, Jochems, and Van Buuren (2004) defined a social space as the network of social relationships amongst group members embedded in group structures of norms and values, rules and roles, beliefs and ideals. A social space is 'sound' if it is characterized by affective work relationships, strong group cohesion, trust, respect and belonging, satisfaction, and a strong sense of community. The Social Space Scale was developed to isolate the social space aspects which are implicitly measured by most existing social presence measures. The Social Space Scale has two dimensions: Positive Group Behavior and Negative Group Behavior, each containing 10, 5-point Likert scale items. The Social Space Scale has a high internal consistency (Cronbach's alphas are .92 and .87 for Positive Group Behavior- and Negative Group Behavior respectively). A moderate correlation between the aggregate scores of the items of the Positive Group Behavior dimension of the Social Space Scale and the items of the Social Presence Scale was expected because, based upon the theoretical discussions in the previous sections, social presence is hypothesized to affect social interaction in that it facilitates socio-emotional processes which may result in a sound social space. Predicting the correlation between the aggregates scores of the items of the Social Presence Indicators and the items of the Negative Group Behavior dimension of the Social Space Scale is more difficult. Research on social presence theory has suggested that CMC low in social presence may cause deindividuation and depersonalization effects, possibly leading to uninhibited behavior (Jessup, Connolly, \& Tansik, 1990). Walther's (1992) social information processing theory, on the other hand, rebuts these suggestions. Therefore, no prediction with respect to possible correlation was made.

The (Dutch language) Sociability Scale measures the degree of perceived sociability of a CSCL environment. Kreijns, Kirschner, Jochems, and van Buuren (2007) defined sociability as the extent the CSCL environment is able to facilitate socio-emotional processes which aim at the emergence of a social space. The Sociability Scale - as was the Social Space Scale - was developed to isolate aspects dealing with those properties of the CSCL environment that make it more inviting for informal and chance social interactions. For example, a room that has uncomfortable chairs and tables is probably not very inviting for people to stay there and converse, while a room with these 'social affordances' probably is. Some fast food restaurants are accused of designing their spaces so as to allow customers to sit long enough to eat their meal, but that hamper sitting too long and socializing. The scale is one-dimensional and contains 10, 5-point Likert scale items. Like the Social Space Scale, this Sociability Scale has a high internal validity (Cronbach's alpha $=.92)$. A moderate correlation between the aggregates scores of the items of the Sociability Scale and that of the Social Presence Scale was expected because sociability is concerned with aspects of person-to-person and group awareness (for awareness see, Kreijns, Kirschner, \& Jochems, 2002) which directly affects the degree of social presence experienced.

Gunawardena (1995) used a 17-item, 5-point bipolar scale questionnaire to assess a range of feelings students have towards CMC, all of which she equates to perceived social presence. The items of this scale were 
translated into Dutch. A moderate correlation between the aggregates scores of the items of the Social Presence Indicators and of the items of the Social Presence Scale was expected (see earlier discussion of this scale)

because only a part of the instrument measures social presence with the rest measuring sociability, social space, and other variables.

The GZ Social Presence Scale (Gunawardena \& Zittle, 1997) is an alternative scale for measuring social presence. The GZ Social Presence Scale consists of 14, 5-point Likert-scale items (see earlier discussion of this scale). The items of the GZ Social Presence Scale were slightly adapted to fit the particular setting and were translated into Dutch. A moderate correlation between the aggregates scores of the items of the GZ Social Presence Scale and of the items of the Social Presence Scale was expected because only a part of the scale measures social presence with the rest measuring sociability, social space, and other variables.

Price and Mueller (1986) developed the Work Group Cohesion Index to measure work-group cohesion in an organizational context. Work-group cohesion is "the extent to which employees have close friends in their immediate work units" (p. 252). Students in a distributed learning group were considered similar to employees in their immediate work unit. The Work Group Cohesion Index consists of five, 5-point Likert scale items. The items were translated into Dutch. The correlation between the aggregated scores of the items of the Work Group Cohesion Index and of the items of our Social Presence Scale was expected to be moderate because though social presence and social cohesiveness mutually affect each other (Yoo \& Alavi, 2001), they are not the same.

Fiedler (1967) developed the Group Atmosphere Scale, an 8-point scale for determining the atmosphere in a group as perceived by the group members. Items of the Group Atmosphere Scale were translated into Dutch and were modified to 5-point scales to concur with the other scales used. Social presence affects social space and, thus, indirectly contributes to group atmosphere (social climate). Consequently, a moderate correlation between the aggregated scores of the items of the Group Atmosphere Scale and the items of our Social Presence Scale was expected. Because the Group Atmosphere Scale is very similar to Gunawardena's Social Presence Indicators, the correlation was expected to be of the same magnitude as the correlation between the aggregated scores of the items of the Social Presence Indicators and of the items of the Social Presence Scale.

\subsection{Refinement of the Raw Social Presence Scale}

The raw Social Presence Scale consisted of eight items, which were reduced to five items to derive a onedimensional social presence measure. First, two items were removed that did not accurately assess the psychological sensation associated with social presence. Principal Component Factor Analysis (no rotation) on the remaining six items revealed two factors with one item loaded equally strong on both factors. This item was removed. Table 9.1 depicts the refined Social Presence Scale. A second Principal Component Factor Analysis (no rotation) was performed on the five test items of the refined scale to obtain the factor loadings on the first and only factor. This factor explained $57.17 \%$ of the total variance.

\section{Results}

\subsection{Internal Consistency and Validity of the Scales}

The Social Presence Scale has a high internal consistency (Cronbach's alpha $=.81$ ). The content validity of the scales was established via a test face-validity. The items were developed based upon a search in the literature regarding social presence, telepresence, social interaction via CMC, group development and group dynamics, trust building, and creating sense of community. The authors of this article then assessed items.

\subsection{Pearson Bi-variate Correlations}

A Pearson bi-variate correlation (2-tailed) analysis was carried out on the aggregate scores of the test items of each measure involved (see Instrumentation). Table 2 depicts the correlations with respect to the Social Presence Scale.

Table 2 Pearson Bi-Variate Correlation Coefficients between the Social Presence Scale and the Other Scales (Text in parentheses reflects our predictions)

\begin{tabular}{|c|c|c|c|c|c|c|c|}
\hline \multirow[t]{4}{*}{ Measure } & \multirow{4}{*}{$\begin{array}{l}\text { Sociability } \\
\text { Scale }\end{array}$} & \multicolumn{2}{|c|}{ Social Space Scale } & \multirow{4}{*}{$\begin{array}{l}\text { Social } \\
\text { Presence } \\
\text { Indicators }\end{array}$} & \multirow{4}{*}{$\begin{array}{l}\text { GZ Social } \\
\text { Presence } \\
\text { Scale }\end{array}$} & \multirow{4}{*}{$\begin{array}{l}\text { Work Group } \\
\text { Cohesion } \\
\text { Index }\end{array}$} & \multirow{4}{*}{$\begin{array}{l}\text { Group } \\
\text { Atmosphere } \\
\text { Scale }\end{array}$} \\
\hline & & Positive & Negative & & & & \\
\hline & & Group & Group & & & & \\
\hline & & Behavior & Behavior & & & & \\
\hline Social & $.63 * *$ & $.53 * *$ & -.10 & $.66 * *$ & $.62 * *$ & $.44 * *$ & $.54 * *$ \\
\hline Prese & (modes & (moderate) & (?) & (modera & $(\bmod$ & (moder & $(\mathrm{mo}$ \\
\hline
\end{tabular}


Scale
$* * p<.01,2$-tailed.
$* p<.05,2$-tailed.

As can be seen, the correlations vary between .44 and .66, which are at the low- and high end of the continuum that characterize moderate correlations (accounting for between $19 \%$ and $44 \%$ of the variance). The correlations between the aggregated scores of the Social Presence Scale and the Work Group Cohesion Index and the Group Atmosphere Scale are at the low end because social presence only indirectly affects social cohesiveness and group atmosphere through social interaction. The correlation between the aggregate scores of the Social Presence Scale and the Sociability Scale is at the high end because sociability directly affects social presence. The correlations between the aggregate scores of the Social Presence Indicators and of the GZ Social Presence Scale are also at the high-end because, ultimately, these measures were designed for assessing social presence.

\subsection{Factor Analysis of the Sociability, Social Presence, and Social Space Scales}

Finally, a Principal Component Factor Analysis (using Varimax rotation) was carried out on the 10 test items of the refined Sociability Scale, the 5 items of the Social Presence Scale, and the 20 items of the Social Space Scale to determine whether each of the measures assessed an isolated phenomenon (i.e., sociability, social presence and social space) or whether there was overlap. The extraction was, therefore, restricted to only four factors because the purpose of this analysis was not to reveal new factors but to determine the uniqueness of the scales with respect to each other. Because the Social Space Scale has two dimensions and both the Sociability Scale and the Social Presence scale only one, the restriction was set to four. The results of the factor analysis are presented in Table 3. From this table it can be seen that each of the three scales indeed measure an isolated phenomenon.

Table 3

Factor Analysis on the Scores of the Items of the Sociability Scale, Social Presence Scale, and the Social Space Scale

\begin{tabular}{llcc}
\hline No. Item & \multicolumn{2}{c}{ Factors } \\
Item & Sociability $\begin{array}{c}\text { Social } \\
\text { Positive Negative } \\
\end{array}$ & Presence Group Group & Group \\
Behavior Behavior
\end{tabular}

\section{Sociability Scale}

1 This CSCL environment enables me to easily contact my team mates

2 I do not feel lonely in this CSCL environment

3 This CSCL environment enables me to get a good impression $\quad .71$ of my team mates

4 This CSCL environment allows spontaneous informal conversations

5 This CSCL environment enables us to develop into a well performing team relationships with my team mates

7 This CSCL environment enables me to identify myself with

9 This CSCL environment allows for non task-related conversations

10 This CSCL environment enables me to make close friendships with my team mates

Social Presence Scale

1 When I have real-time conversations in this CSCL environment, I have my communication partner in my mind's eye

2 When I have asynchronous conversations in this CSCL environment, I also have my communication partner in my mind's eye 
environment, I feel that I deal with very real persons and not with abstract anonymous persons

environment, I also feel that I deal with very real persons and not with abstract anonymous persons

5 Real-time conversations in this CSCL environment can hardly be distinguished from face-to-face conversations

Positive Group Behavior

1 Group members felt free to criticize the ideas, statements,

and/or opinions of others

2 We reached a good understanding on how we had to function

Group members ensured that we kept in touch with each other $\quad .77$

We worked hard on the group assignment

I maintained contact with all other group members

Group members gave personal information on themselves

The group conducted open and lively conversations and/or discussions

8 Group members took the initiative to get in touch with others

9 Group members spontaneously started conversations with others

10 Group members asked others how the work was going

Negative Group Behavior

11 Group members felt that they were attacked personally when

their ideas, statements and/or opinions were criticizeda

12 Group members were suspicious of othersa

Group members grew to dislike othersa

I did the lion's share of the worka

14 I did the lion's share of the worka

17 Group members disagreed amongst each othera

19 Group members gossiped about each othera

$a$ These items were reverse coded for analysis.

\section{Discussion}

It is clear from the results that social presence is a unique construct and that existing instruments for determining its degree of presence are inadequate. The results of this study, both empirical and nomological, unequivocally show that the instrument designed here, if nothing else, is an important step in the right direction.

The validation of the social presence measure, however, does have some weak points. First, the number of cases was 79. A general rule of the thumb is that there must be at least five to ten cases per item when performing a factor analysis. The raw Social Presence Scale initially contained eight items, implying that we needed between 40 and 80 cases. This condition was fulfilled. However, the factor analysis involving the three measures actually required between 175 and 350 cases, and this condition was not fulfilled. Second, three samples were collapsed in order to obtain the 79 cases and not one homogenous sample. A mitigating circumstance here is that earlier internal research at the OUNL with respect to student characteristics shows that the student populations for these courses do not differ. Third, the same cases for the factor analysis were used as on the test items of the refined Sociability Scale, the Social Presence Scale, and the Social Space Scale. Due to this, the result (Table 3) might benefit from the chance characteristic of the 79 cases from which the Social Presence Scale (and the two other measures) was derived.

In other words, though the results are very promising, the findings only suggest that the Social Presence Scale has potential to be useful as measures for measuring social presence. More research is needed to corroborate the findings here. 


\section{References}

Archer, W, Garrison, D. R., Anderson, T., Rourke, L. (2001). A framework for analyzing critical thinking in computer conferences. In P. Dillenbourg, A. Eurlings, \& K. Hakkarainen (Eds.), Proceedings of the 1st European conference on computer-supported collaborative learning: European perspectives on computer-supported collaborative learning (pp. 59-66). Maastricht: Maastricht McLuhan Institute.

Andersen, J. (1979). Teacher immediacy as a predictor of teaching effectiveness. In D. Niimo (Ed.), Communication yearbook 3 (pp. $543-$ 559). New Brunswick, NJ: Transaction Books.

Argyle, M., \& Dean, J. (1965). Eye contact, distance and affiliation. Sociometry, 28, 289-304.

Cobb, S. C. (2009). Social presence and online learning: A current view from a research perspective. Journal of Interactive Online Learning, $8(3), 241-254$

Fiedler, F. E. (1962). Leader attitudes, group climate, and group creativity. Journal of Abnormal and Social Psychology, 65, 308-318.

Fiedler, F. E. (1967). A theory of leadership effectiveness. New York: McGraw-Hill.

Fulk, J., Schmitz, J., \& Steinfield, C. W. (1990). A social influence model of technology use. In J. Fulk \& C. W. Steinfield (Eds.), Organizations and Communication Technology (pp. 117-140). London and Newbury Park, CA: Sage.

Garramone, G. M., Harris, A. C., \& Anderson, R. (1986). Uses of political computer bulletin boards. Journal of Broadcasting \& Electronic Media, 30, 325-339.

Garrison, D. R. (1993). A cognitive constructivist view of distance education: An analysis of teaching-learning assumptions. Distance Education, 14, 199-211

Garrison, D. R. (1997a). Computer conferencing: The post-industrial age of distance education. Open Learning, 12 (2), 3-11.

Garrison, D. R. (June, 1997b). Computer conferencing in distance education: Cognitive and social presence issues. In Proceedings of the 18th World conference of the International council for distance education (ICDE): The new learning environment: A global perspective. Pennsylvania: Pennsylvania State University.

Garrison, D. R. \& Anderson, T. (2003). E-learning in the 21st century. London: Routledge Falmer.

Garrison, D. R., Anderson, T., \& Archer, W. (2000). Critical thinking in a text-based environment: Computer conferencing in higher education. Internet and Higher Education, 11(2), 1-14.

Gunawardena, C. N. (1995). Social presence theory and implications for interaction and collaborative learning in computer conferences. International Journal of Educational Telecommunications, 1(2/3), 147-166.

Gunawardena, C. N., \& Zittle, F. (1997). Social presence as a predictor of satisfaction within a computer mediated conferencing environment. American Journal of Distance Education, 11(3), 8-25.

Hills, A. (2005). Social presence and communication quality in videoconferencing. Unpublished bachelor dissertation, University of Otago, New Zealand

Hiltz, S. R. (1994). The Virtual Classroom: Learning without limits via computer networks. Norwood, NJ: Ablex Publishing Corporation.

Jacques, D. (1992). Learning in groups (2nd ed.). London: Kogan Page.

Jessup, L. M., Connolly, T., \& Tansik, D. A. (1990). Toward a theory of automated group work: The deindividuating effects of anonymity. Small Group Research, 21, 333-348.

Johnson, R. T., Johnson, D. W., \& Stanne, M. B. (1985). Effects of cooperative, competitive, and individualistic goal structures on computerassisted instruction. Journal of Educational Psychology, 77, 668-677.

Kearsley, G. (1995). The nature and value of interaction in distance learning. (ACSDE Research Monograph No. 12, pp. 83-92). University Park, PA: Pennsylvania State University, American Center for the Study of Distance Education.

Koh, J., Kim, Y.-G., Butler, B., Bock, G.-W. (2007). Encouraging participation in virtual communities. Communications of the ACM. 50(2), 69-73.

Kreijns, K., Kirschner, P. A., \& Jochems, W. (2002). The sociability of computer-supported collaborative learning environments. Journal of Education Technology \& Society, 5(1), 8-22.

Kreijns, K., Kirschner, P. A., \& Jochems, W. (2003). Identifying the pitfalls for social interaction in computer-supported collaborative learning environments: A review of the research. Computers in Human Behavior, 19, 335-353.

Kreijns, K., Kirschner, P. A., Jochems, W., \& Van Buuren, H. (2004). Measuring perceived quality of social space in distributed learning groups. Computers in Human Behavior, 20, 607-632.

Kreijns, K., Kirschner, P. A., Jochems, W., \& Van Buuren (2007). Measuring Perceived Sociability of Computer-Supported Collaborative Learning Environments. Computers \& Education, 49, 176-192.

Lin, G.-Y. (2004, October 19-23). Social Presence Questionnaire of Online Collaborative Learning: Development and Validity. Paper presented at the 27th Association for Educational Communications and Technology (AECT) Covention. Chicago, IL.

Liu, S. Y., Gomez, J., \& Yen, C-J., (2009). Community college online course retention and final grade: Predictablility of social presence. Journal of Interactive Online Learning, 8(2), 165-182.

Lombard, M. \& Ditton, T. (1997). At the heart of it all: The concept of presence. Journal of Computer-Mediated Communication, 3(2). Retrieved January 29, 2003, from http://www.ascusc.org/jcmc/vol3/issue2/lombard.html.

Lowenthal, P. R. (2010). The evolution and influence of social presence theory on online learning. In T. T. Kidd (Ed.), Online Education and Adult Learning: New Frontiers for Teaching Practices (pp. 124-134). Hershey, PA: IGI Global.

Osgood, C. E., Suci, G. J., \& Tannenbaum, P. H. (1957). The measure of meaning. Urbana, IL: University of Illinois Press.

Price, J. L., \& Mueller, C. W. (1986). Handbook of organizational measurement. Marshfield, MA: Pitman Publishing.

Rice, R. E. (1993). Media appropriateness: Using social presence theory to compare traditional and new media. Human Communication Research, 19, 451-484.

Rourke, L., \& Anderson, T. (2002) Exploring social communication in asynchronous, text-based computer conferencing. Journal of Interactive Learning Research, 13, 259-275.

Rourke, L., Anderson, T., Garrison, D. R., \& Archer, W. (1999). Assessing social presence in asynchronous, text-based computer conferences. Journal of Distance Education, 14(3), 51-70.

Shen, K. N., Khalifa, M., \& Yu, A Y. (2006, August 4-6). Supporting social interaction in virtual communities: Role of social presence. Paper presented at the 12th Americas conference on Information systems. Acapulco, Mexico.

Short, J., Williams, E., \& Christie, B. (1976). The social psychology of telecommunications. London: John Wiley \& Sons, Ltd.

Slavin, R. (1995). Cooperative learning: Theory, research, and practice (2nd ed.). Needham Heights, MA: Ally and Bacon.

Soller, A. L., \& Lesgold, A., Linton, F., Goodman, B. (1999). What makes peer interaction effective? Modeling effective communication in an intelligent CSCL. In Proceedings of the 1999 AAAI fall symposium: Psychological models of communication in collaborative systems (pp. 116-123). Cape-Cod, MA.

Spears, R., Postmes, T., Wolbert, A., Lea, M., \& Rogers, P. (2000). Social psychological influence of ICT on society and their policy implications [Electronic version]. Amsterdam: Infodrome. 
Stacey, E. (2000). Quality online participation : establishing social presence. In Research in distance education 5: Revised papers from the 5th Research in distance education conference (pp. 138-153). Melbourne, Vict. :Deakin University.

Stacey, E. (2002). Social presence online: networking learners at a distance. Education and Information Technologies, 7, 287-294.

Steinfield, C. (1986). Computer-mediated communication in an organizational setting: Explaining task-related and socioemotional uses. In M. L. McLaughlin (Ed.), Communication Yearbook 9 (pp. 777-804). Newbury Park, CA: Sage

Swan, K. (2002). Building learning communities in online courses: The importance of interaction. Education, Communication and Information, 2(1), 23-50.

Towell, J., \& Towell, E. (1997). Presence in text-based networked virtual environments or “MUDS.” Presence. Teleoperators and Virtual Environments 6, 590-595.

Tu, C. H. (1997). Using CMC to increase the social presence of Chinese students. Paper presented at the Association for Educational Communication and Technology (AECT) annual conference, Albuquerque, NM.

Tu, C. H. (2000a). On-line learning migration: From social learning theory to social presence theory in a CMC environment. Journal of Network and Computer Applications, 23(1), 27-37.

Tu, C. H. (2000b). Critical examination of factors affecting interaction on CMC. Journal of Network and Computer Applications, 23(1), 3958.

Tu, C. H. (2001). How Chinese perceive social presence: An examination of an online learning environment. Educational Media International, 38(1), 45-60.

Tu, C. H. (2002a). The relationship between social presence and online privacy. Internet and Higher Education, 5, 293-318.

$\mathrm{Tu}, \mathrm{C}$. H. (2002b). The measurement of social presence in an online learning environment. International Journal on E-learning, 1(2), 34-45.

Tu, C, H. (2002c). The impacts of text-based CMC on online social presence. The Journal of Interactive Online Learning, 1(2), 1-24.

Tu, C. H., \& McIsaac, M. (2002). An examination of social presence to increase interaction in online classes. American Journal of Distance Education, 16(3), 131-150.

Walther, J. B. (1992). Interpersonal effects in computer-mediated interaction: A relational perspective. Communication Research, 19(1), 5290

Walther, J. B., \& Burgoon, J. K. (1992). Relational communication in computer-mediated interaction. Human Communication Research, 19(1), 50-88.

Wiener, M., \& Mehrabian, A. (1968). Language within language: Immediacy, a channel in verbal communication. New York: AppletonCentury-Crofts.

Witmer, D. F. (1997). Risky business: why people feel safe in sexually explicit on-line communication. Journal of Computer Mediated Communication, 2(4). Retrieved January 29, 2005, from http://www.ascusc.org/jcmc/vol2/issue4/witmer2.html.

Yoo, Y., \& Alavi, M. (2001). Media and group cohesion: Relative influences on social presence, task participation, and group cohesiveness, MIS Quarterly, 25, 371-390. 


\begin{abstract}
Social presence - the degree to which 'the other' in a communication appears to be a 'real' person has captured the attention of those dealing with learning in groups through computer-supported collaborative learning environments. The concept is important because it affects participation and social interaction, both necessary for effective collaboration and knowledge construction. This article reports on the construction and validation of a self-reporting (Dutch-language) Social Presence Scale to determine perceived social presence in distributed learning groups using computer-supported collaborative learning environments. The result is a onedimensional scale consisting of five items with an internal consistency of .81 . We used a nomological network of similar constructs for further validation. The findings suggest that the Social Presence Scale has potential to be useful as a measure for social presence.
\end{abstract}

Keywords Social Presence, Social Presence Scale, Sociability, Social Affordances

\title{
1 Introduction
}

In synchronous and asynchronous learning groups social presence (Short, Williams, \& Christie, 1976) is an important determinant for both participation (Koh, Kim, Butler, \& Bock, 2007; Shen, Khalifa, \& Yu, 2006; Stacey, 2000) and social interaction (Cobb, 2009; Garrison, 1997; Garrison \& Anderson, 2003; Lowenthal, 2010; Stacey, 2002; Swan, 2002; Tu \& McIsaac, 2002). Inspired by telepresence research (Lombard \& Ditton, 1997) we define social presence as the degree of illusion that others appear to be a 'real' physical persons in either an immediate (i.e., real time/synchronous) or a delayed (i.e., time-deferred/asynchronous) communication episode. If "social presence is low, the foundation of social learning, social interaction, does not occur" (Tu, 2000a, p. 30; cf., Garramone, Harris, \& Anderson, 1986). Tu (2000a), linking social learning theory to social presence, took this a step further when he asserted that social presence "is required to enhance and foster online social interaction, which is the major vehicle of social learning" (p. 27). And, since social presence is so important for maintaining a high degree of online social interaction, it "is a significant predictor of course retention and final grade in the community college online environment" (Liu, Gomez, and Yen, 2009, p. 165).

Social interaction has long been seen as a prerequisite for collaborative learning and knowledge construction (Hiltz, 1994; Kearsley, 1995; Slavin, 1995). Garrison (1993) suggested that it promotes explanation and helps develop critical perspectives on a problem, leading to true meaning. Soller, Lesgold, Linton, and Goodman (1999) saw it as instrumental in making peer interaction more effective since students "learning effectively in groups encourage each other to ask questions, explain and justify their opinions, articulate their reasoning, and elaborate and reflect upon their knowledge" (p. 116). Johnson, Johnson, and Stanne (1985) emphasized that "the cognitive processes most necessary for deeper level understanding and the implanting of information into memory, such as elaboration and metacognition, occur only through dialogue and interaction with other people" (p. 675).

In addition, social interaction is also important for socio-emotional and social processes related to group formation and group dynamics affecting affiliation, impression formation, developing affective relationships, and building social cohesiveness and community. Only when groups attain strong social cohesiveness, trust, belonging, and a sense of community can they effectively accomplish their learning tasks (Gunawardena, 1995; Gunawardena \& Zittle, 1997; Jacques, 1992; Kreijns, Kirschner, \& Jochems, 2003).

This study is the third in a series of experiments to develop instruments for determining how users of CSCL environments experience those environments. The first (Kreijns, Kirschner, Jochems, \& Van Buuren, 2004) produced an instrument for determining social space and the second (Kreijns, Kirschner, Jochems, \& Van 
Buuren, 2007) one for determining sociability. This study has resulted in an instrument for determining social presence.

\section{Short, Williams, and Christie's Social Presence Theory}

Short, Williams, and Christie's (1976) social presence theory explains the interpersonal effects occuring between two interlocutors when communicating, regardless of the medium. They characterized different media in terms of their potential to communicate verbal and non-verbal cues conveying socio-emotional information such that the other is perceived as 'physically' present. Non-verbal cues can be visual (e.g., facial expression, posture), auditory (e.g., voice volume, inflection), tactile (e.g., touching, shaking hands), and olfactory (e.g., smells). Short et al. defined social presence as the "degree of salience of the other person in the interaction and the consequent salience of the interpersonal relationships [that] varies between different media, [affecting] the nature of the interaction and [interacting] with the purpose of [influencing] the medium chosen by the individual who wishes to communicate" (p. 65). In their initial view, they held that the physical and technological characteristics of a medium were solely responsible for its degree of social presence; an objective quality of the communication medium. They eventually relaxed their view to include subjective qualities of the medium (Walther \& Burgoon, 1992).

Social presence theory has often been used to rank telecommunication media according their degree of social presence (i.e., face-to-face > video-conferencing > audio). According to the theory, media higher in social presence are more appropriate for carrying-out interpersonal tasks (Rice, 1993; Steinfield, 1986). In other words, developing and maintaining mutual trust in tasks that require conflict-resolution or negotiation require communication media which are high in social presence because these media are more effective for trust building and, consequently, social influence (Fulk, Schmitz, \& Steinfield, 1990). It hypothesizes that mediachoice can be predicted such that "users of any given communications medium are in some sense aware of the degree of Social Presence of the medium and tend to avoid using the medium for certain types of interactions; specifically, interactions requiring a higher degree of Social Presence than they perceive the medium to have" (Short et al, 1976, p. 65).

Finally, Short et al (1976) related two other social psychological concepts to social presence, namely intimacy (Argyle \& Dean, 1965) and immediacy (Wiener \& Mehrabian, 1968). According to Argyle and Dean's equilibrium theory, communicating participants reach an optimal level of intimacy where conflicting approach and avoidance forces are in equilibrium. Immediacy, is a "measure of the psychological distance which a communicator puts between himself [sic] and the object of his communication, his addressee or his communication...negative affect, low evaluation and non-preference for any of these things are associated with non-immediacy in communications" (Short et al, p. 72). According to Gunawardena (1995), immediacy enhances social presence.

\section{Towards an Alternative Measure of Social Presence}

Though social presence theory is both useful and attractive, it does have a number of problems. Lowenthal (2010), for example, pointed out that "despite its intuitive appeal, researchers and practitioners alike often define and conceptualize this popular construct differently. In fact, it is often hard to distinguish between whether someone is talking about social interaction, immediacy, intimacy, emotion, and/or connectedness when they talk about social presence" (p. 125). A number of these problems are discussed in the following subsections.

\subsection{Technological versus social determism}

Social presence theory is a prime example of technological determinism; the idea that it is a society's technology that drives the development of its social structure and cultural values. In the view of Short et al. (1976), it is the technology that determines the perception of social presence. In contrast, others (e.g., Gunawardena, 1995; Tu, $2002 \mathrm{~b}$ ) argued that in the perception of social presence, media attributes are irrelevant. The social factors are what are important. These two extremes illustrate what Spears, Postmes, Wolbert, Lea, and Rogers (2000) called the 'technological vs. social determinism' controversy. In their eyes, 'simple' theories over-generalize ICTs' social effects by assuming "that ICTs' effects are due to characteristics of the technology or that these are constructed by social factors" (p. 8). They found that "the diversity of social effects precludes that technology is singularly good or bad, and that technology determines the social effects. Conversely, social determinism [ - the idea that social interactions and constructs alone determine individual behavior - ] cannot account for invariable technological effects: not every use of ICTs is as flexible as these theories claim. Moreover, social determinism often is relativistic, which restricts its power of prediction and practical use... a theory of the social effects of ICT must emphasize that the use and effect of the new technologies are co-determined by technological features 
(anonymity, isolation, and asynchrony) and social psychological factors (identities, social relations, and social practices)" (p. 8).

\subsection{Definitions and conceptualization of Social Presence}

Gunawardena (1995) adapted Short et al's (1976) definition. In her view, developing social presence is key to promoting collaborative learning and knowledge building and is a predictor of learner satisfaction (Gunawardena $\&$ Zittle, 1997). She concluded that "although CMC is described as a medium that is low in non-verbal cues and social context cues, participants in conferences create social presence by projecting their identities and building online communities" (p. 163). Garrison, Anderson, and Archer (2000) expanded this perspective defining social presence as "the ability of participants in a community of inquiry to project themselves socially and emotionally, as 'real' people (i.e., their full personality), through the medium of communication being used" (p. 94). They argued that it is important because it functions as "support for cognitive presence, indirectly facilitating the process of critical thinking carried on by the community of learners... and is a direct contributor to the success of the educational experience" (p. 89).

Tu (2000a, 2001, 2002a, 2002b, 2002c) used a variety of definitions of social presence, defining social presence as the degree "of person-to-person awareness, which occurs in a mediated environment" (2002b, p. 34) and "of feeling, perception and reaction of being connected on CMC to another intellectual entity" (2002c, p. 2). In his view, social presence is key to determining the social interaction in group learning, identifying three main variables contributing to social presence, namely:

1. Social context: constructed from the users' characteristics and their perceptions of a CMC environment.

2. Online communication: related to the attributes of the online language and its application.

3. Interactivity: active communication and learning activities that users engage in and the utility of the communication styles.

In agreement with Witmer (1997), Tu (2002a) suggested two other - privacy related - variables that could affect the degree of perceived social presence, namely:

4. System privacy: actual security of CMC technologies offered, including the likelihood that the system will allow unknown others to read, send, or resend messages.

5. Feelings of privacy: "perception of privacy psychologically, mentally, culturally, or conditionally rather than actual security" (p. 297).

\subsection{Measuring Perceived Social Presence}

Although a number of measures exists that purport to measure social presence, close examination of these instruments reveals that each also measures aspects of other constructs such as social climate, social interaction, cohesiveness, social space, and sociability. Also, some measures intended to measure social presence are used to measure other constructs such as social environment or attitude. We present some examples to illustrate this.

The dominant social presence measure was developed by Short et al (1976). They used four, 7-point semantic differential scales to measure the subjective degree of social presence: personal-impersonal, sensitiveinsensitive, warm-cold, and sociable-unsociable. The more personal, sensitive, warm, and sociable the medium is perceived to be, the higher social presence is. However, though their social presence theory is based on objective qualities of media, they based their measure on the subjective qualities of the media. While Walther (1992), questioned whether it is appropriate to determine the degree of social presence from such an objective perspective, we temper this conclusion since in the alternative perspective on social presence -which sees social presence as a psychological sensation- the measure could be valid. A different criticism is made by Tu (2002b) who argued that the four items used are too general to measure such a complicated concept and attacks the semantic differential technique as faulty since different respondents may ascribe different definitions and meanings to the adjectives used as semantic opposites.

Other social presence measures have been developed by Gunawardena (1995), Gunawardena and Zittle (1997) and Tu (2000b). Gunawardena developed her Social Presence Indicators which are 17, 5-point semantic differential scales which includes the four scales developed by Short et al. Alternatively, Gunawardena and Zittle developed a social presence measure which consists of 14, 5-point Likert-scale items (GZ Social Presence Scale). They contended that the Social Presence Indicators measure the intimacy dimension of social presence (Argyle \& Dean, 1965) while the GZ Social Presence Scale measures its immediacy (Wiener \& Mehrabian, 1968).

Tu (2000b) developed his Social Presence and Privacy Questionnaire (SPPQ) to assess five social presence dimensions for e-mail, bulletin board and real-time discussion, namely Social context, Online communication, Interactivity, System privacy, and Feeling of privacy. All items are 5-point Likert scale items, except for one system privacy item. 
A completely different approach is measuring social presence through the analysis of the content of the social expressions (i.e., affective, interactive, cohesive), for example, are used by some as template for such a content analysis.

\subsection{Problems with Existing Social Presence Measures}

A first problem is that it is not unequivocal what the instruments actually measure. In other words: What do the available instruments actually measure? Do they only measure social presence or do they also measure other variables such as attitude, cohesiveness, climate, feelings towards CMC, privacy, degree of interpersonal interaction, and so forth? The problem here seems to be caused by the researchers themselves. Rourke and Anderson (2002), for example, were not consistent in their use of the term social climate. They also used the term 'social environment' and, when referring to the instrument for measuring 'social climate', used the term 'social presence'. Their definition of social presence is based on Garrison et al's (2000) and is, thus, different from Short et al's (1976). In addition, they measured 'social communication' by measuring perceived frequencies of 15 social expressions; Rourke et al (1999) used almost the same social expressions, but this time to measure 'social presence.'

According to Gunawardena (1995), her Social Presence Indicators measure student perception of CMC as a social medium although she defined social presence as "the degree to which a person is perceived as a 'real person' in mediated communication" (p. 151). Obviously, these two definitions are completely different. Also, Gunawardena and Zittle (1997) stated that their GZ Social Presence Scale measures the immediacy dimension of social presence. They, however, also stated that it measures the "perceived sense of 'online community', the degree of social comfort with CMC" (p. 14). According to Lowenthal (2010): "Gunawardena and Zittle as well as Tu focused primarily on studying user's attitude whereas Rourke et al. focused on studying user's behaviors" (p. 131-132).

A second problem is that while the effects of social presence or variables correlated to social presence are measured, they are interpreted as being equal to social presence. In other words; social presence per se is not measured. Tu (2000b), for example, used variables correlated to social presence. Though he stated that "many different variables are cited in the literature that may contribute to the degree of social presence: recipients, topics, privacy, task, social relationship, communication style" (p. 39), some of them are explicitly part his social presence measure.

A third problem is that some of the measures have not been adequately validated. According to Lin (2004) " $[\mathrm{N}]$ o reliability and validity assessments of the social presence instruments developed by Short et al in 1976 \& Gunawardena in 1995 are reported" (p. 588). He further pointed out that "for the instrument developed by Gunawardena \& Zittle in 1997, concurrent validity of the social presence scales was indicated by the strong and positive correlation with bipolar social indicators based on Short et al's instrument; however, the scale itself was not validated" (p. 588). In spite of this serious problem, researchers continue to use these instruments or their derivates (see for example, Cobb, 2009; Hills, 2005).

A fourth problem is that some measures are confined to certain media types. Henniger and Viswanathan (2004), for example, criticized Tu's SPPQ measure for exactly this reason. According to them, Tu's model of scial presence was only examined in a text-based environment, therefore, "this model offers interesting insights into factors influencing social presence; however its scope is very limited due to the restriction to text-based computer-mediated communication"(p. 370).

Finally, content analysis based upon the template provided by Rourke et al (1999) does not give a clear answer as to how to calculate scores from frequencies and how to aggregate the scores of each indicator to provide a single measure of the degree of social presence. First, the frequencies (e.g., the number of vocatives found) are not normalized prohibiting comparisons between samples. Second, it is unclear how to weigh each indicator score (e.g., the number of vocatives can be much, much larger than the number of expressions of humor).

To conclude, existing social presence scales measure varying aspects of an amorphous set of variables including social presence - to varying degrees. This is confounded by the fact that not all scales exhibit the necessary content or construct validity nor do their authors present data regarding internal reliability. This has led us to the conclusion that we ourselves must develop an unequivocal alternative social presence measure.

\section{An Alternative Social Presence Scale}

We developed a self-reporting Social Presence Scale (in Dutch) that measures the perceived degree of social presence in a CSCL environment. Construction of the items in the scale was inspired by telepresence research (e.g., Lombart \& Ditton, 1997) which focused on measuring the degree that individuals feel that they are transported from 'here to there' and that 'they are there' (i.e., the telepresence-effect). Their instruments try to 
capture the 'sensation' of telepresence as a psychological phenomenon without any 'side-effects' In this vein, we constructed a social presence measure capturing the psychological sensation associated with social presence. Table 1 depicts our (refined) Social Presence Scale. The next section will explain how this refinement was achieved and the meaning of the last three columns.

Table 1 The Social Presence Scale

\begin{tabular}{llccc}
\hline $\begin{array}{l}\text { No. } \\
\text { Item }\end{array}$ & Item & $M$ & $S D$ & $\begin{array}{l}\text { Factor } \\
\text { Social Presence }\end{array}$ \\
\hline 1 & $\begin{array}{l}\text { When I have real-time conversations in this CSCL environment, I } \\
\text { have my communication partner in my mind's eye }\end{array}$ & 2.15 & 1.17 & .80 \\
2 & $\begin{array}{l}\text { When I have asynchronous conversations in this CSCL environment, } 2.75 \\
\text { I also have my communication partner in my mind's eye }\end{array}$ & 1.16 & .70 \\
3 & $\begin{array}{l}\text { When I have real-time conversations in this CSCL environment, I } \\
\text { feel that I deal with very real persons and not with abstract } \\
\text { anonymous persons }\end{array}$ & 2.90 & 1.50 & .79 \\
& $\begin{array}{l}\text { When I have asynchronous conversations in this CSCL environment, 3.56 } \\
\text { I also feel that I deal with very real persons and not with abstract } \\
\text { anonymous persons } \\
\text { Real-time conversations in this CSCL environment can hardly be } \\
\text { distinguished from face-to-face conversations }\end{array}$ & 1.21 & .79 \\
5 & 1.01 & .69
\end{tabular}

Note. Judgments were made on 5-point Likert scales (1 = not applicable at all; 2 = rarely applicable; $3=$ moderately applicable $; 4$ = largely applicable $; 5=$ totally applicable $)$.

\section{Method}

\subsection{Participation}

Students in three distance education courses at the Open University of the Netherlands (OUNL) participated in the study. In the first course (environmental policy), 35 students ( 25 males, 10 females) from four higher education institutions participated: OUNL ( 8 males, 2 females), Maastricht University (MU; 3 males, 6 females), Twente University (TU; 7 males, 1 female), and Fontys University of Applied Sciences (Fontys; 7 males, 1 female). OUNL- and MU students were combined and assigned to one of five groups; four groups had 4 participants, the remaining group had 3 participants. All TU students were assigned to one group of 8 participants. Finally, Fontys students were assigned to one of two groups; both groups had 4 participants. All groups were required to write an environmental advisory report and made use of eRoom® version 4.0 to do this. In the second course (on statistics), 38 adult undergraduates (all OUNL; 6 male, 32 female) were randomly assigned to one of seven groups consisting of 5 or 6 members each. Among these students, 2 female students were non-starters (i.e., they did not participate from the very beginning of the course). During the course, 10 students ( 2 males, 8 females) dropped out. Consequently, group sizes were decreased; four groups ended up with 3 participants, one group had 4 and the remaining two groups had 5 . All groups had to study the same study-material and had to produce a concept research paper, making use of Studynet, the CSCL environment of the OUNL, which makes use of newsgroups for asynchronous communication and Microsoft ${ }^{\circledR}$ Netmeeting ${ }^{\mathrm{TM}}$ for synchronous communication. Use of telephone and e-mail were prohibited.

One hundred thirteen adult undergraduates (all OUNL; 24 male, 79 female) were enrolled in a third course (also on statistics). Students were randomly assigned to one of eight 'slow' groups, one of eight 'fast' groups, or one of two 'free' groups (in total 18 groups). Slow and free groups had approximately twice the time allotted to fast groups to complete the course (10 months and 6 months respectively). Collaboration was compulsory for the slow and fast groups, and voluntary for the free groups. Half of the slow groups and half of the fast groups had 4 members; the remaining slow and fast groups had 8 . The free groups had 5 and 12 participants. Among them, 6 female students were non-starters. During the course 14 students dropped out (4 males, 10 females) and 18 students moved to another group. Consequently, groups changed in composition and size. All groups had to study questionnaire use, moderation analysis with ANOVA, and regression analysis methods. Students had to use the same environment as the second course.

\subsection{Procedure}

Course 1 lasted 14 weeks. In that period, there were three face-to-face meetings, namely a kick-off meeting, an evaluation meeting halfway through the course, and a closing meeting. Immediately after the second face-to-face meeting, - in addition to the Social Presence Scale - a Social Space Scale, a Sociability Scale and all other scales 
discussed in the next section were administered electronically (using Dipolar Professional Quest ${ }^{\mathrm{TM}}$ software, release 2.2). From the 35 students, 11 (31.4\%) responded to the questionnaire of which $9(25.7 \%)$ responded to all items. All respondents were either OUNL- or MU students. Although response was low, we had agreed with those responsible for the course that students were to be asked only once to fill in the questionnaire.

The second course lasted 18 weeks in which three face-to-face meetings were organized. The same electronic questionnaire was launched. From the 26 students that actually participated (38 minus non-starters and dropouts) 18 (69.2\%) responded.

The third course had a variable length. Slow and free groups had 10 months to complete the course while fast groups had 6. At the time the questionnaire was launched, slow and free groups were still studying while the fast groups had already completed the course. From the 93 students that still participated (113 minus non-starters and dropouts), $50(53.8 \%)$ responded. Two students who dropped out also returned the questionnaire. The total number of respondents is therefore, 52. In more detail: from the 29 students in the fast groups, 20 (69.0\%) responded; from the 41 students in the slow groups, 20 (48.8\%) responded plus 1 drop-out. From the 23 students in the free groups, 10 (43.5\%) responded plus 1 drop-out.

\subsection{Instrumentation}

The validation process used six measures dealing with constructs related to the social presence construct, namely:

1. Social Space Scale (Kreijns, Kirschner, Jochems, \& Van Buuren, 2004)

2. Sociability Scale (Kreijns, Kirschner, Jochems, \& Van Buuren, 2007)

3. Social Presence Indicators (Gunawardena, 1995)

4. Social Presence Scale (Gunawardena \& Zittle, 1997)

5. Work-Group Cohesiveness Index (Price \& Mueller, 1986)

6. Group Atmosphere Scale (Fiedler, 1962, 1967)

The (Dutch language) Social Space Scale measures the degree of perceived quality of a social space existing in a distributed learning group, synchronous or asynchronous. Kreijns, Kirschner, Jochems, and Van Buuren (2004) defined a social space as the network of social relationships amongst group members embedded in group structures of norms and values, rules and roles, beliefs and ideals. A social space is 'sound' if it is characterized by affective work relationships, strong group cohesion, trust, respect and belonging, satisfaction, and a strong sense of community. The Social Space Scale was developed to isolate the social space aspects which are implicitly measured by most existing social presence measures. The Social Space Scale has two dimensions: Positive Group Behavior and Negative Group Behavior, each containing 10, 5-point Likert scale items. The Social Space Scale has a high internal consistency (Cronbach's alphas are .92 and .87 for Positive Group Behavior- and Negative Group Behavior respectively). A moderate correlation between the aggregate scores of the items of the Positive Group Behavior dimension of the Social Space Scale and the items of the Social Presence Scale was expected because, based upon the theoretical discussions in the previous sections, social presence is hypothesized to affect social interaction in that it facilitates socio-emotional processes which may result in a sound social space. Predicting the correlation between the aggregates scores of the items of the Social Presence Indicators and the items of the Negative Group Behavior dimension of the Social Space Scale is more difficult. Research on social presence theory has suggested that CMC low in social presence may cause deindividuation and depersonalization effects, possibly leading to uninhibited behavior (Jessup, Connolly, \& Tansik, 1990). Walther's (1992) social information processing theory, on the other hand, rebuts these suggestions. Therefore, no prediction with respect to possible correlation was made.

The (Dutch language) Sociability Scale measures the degree of perceived sociability of a CSCL environment. Kreijns, Kirschner, Jochems, and van Buuren (2007) defined sociability as the extent the CSCL environment is able to facilitate socio-emotional processes which aim at the emergence of a social space. The Sociability Scale - as was the Social Space Scale - was developed to isolate aspects dealing with those properties of the CSCL environment that make it more inviting for informal and chance social interactions. For example, a room that has uncomfortable chairs and tables is probably not very inviting for people to stay there and converse, while a room with these 'social affordances' probably is. Some fast food restaurants are accused of designing their spaces so as to allow customers to sit long enough to eat their meal, but that hamper sitting too long and socializing. The scale is one-dimensional and contains 10, 5-point Likert scale items. Like the Social Space Scale, this Sociability Scale has a high internal validity (Cronbach's alpha $=.92)$. A moderate correlation between the aggregates scores of the items of the Sociability Scale and that of the Social Presence Scale was expected because sociability is concerned with aspects of person-to-person and group awareness (for awareness see, Kreijns, Kirschner, \& Jochems, 2002) which directly affects the degree of social presence experienced.

Gunawardena (1995) used a 17-item, 5-point bipolar scale questionnaire to assess a range of feelings students have towards CMC, all of which she equates to perceived social presence. The items of this scale were 
translated into Dutch. A moderate correlation between the aggregates scores of the items of the Social Presence Indicators and of the items of the Social Presence Scale was expected (see earlier discussion of this scale) because only a part of the instrument measures social presence with the rest measuring sociability, social space, and other variables.

The GZ Social Presence Scale (Gunawardena \& Zittle, 1997) is an alternative scale for measuring social presence. The GZ Social Presence Scale consists of 14, 5-point Likert-scale items (see earlier discussion of this scale). The items of the GZ Social Presence Scale were slightly adapted to fit the particular setting and were translated into Dutch. A moderate correlation between the aggregates scores of the items of the GZ Social Presence Scale and of the items of the Social Presence Scale was expected because only a part of the scale measures social presence with the rest measuring sociability, social space, and other variables.

Price and Mueller (1986) developed the Work Group Cohesion Index to measure work-group cohesion in an organizational context. Work-group cohesion is "the extent to which employees have close friends in their immediate work units" (p. 252). Students in a distributed learning group were considered similar to employees in their immediate work unit. The Work Group Cohesion Index consists of five, 5-point Likert scale items. The items were translated into Dutch. The correlation between the aggregated scores of the items of the Work Group Cohesion Index and of the items of our Social Presence Scale was expected to be moderate because though social presence and social cohesiveness mutually affect each other (Yoo \& Alavi, 2001), they are not the same.

Fiedler (1967) developed the Group Atmosphere Scale, an 8-point scale for determining the atmosphere in a group as perceived by the group members. Items of the Group Atmosphere Scale were translated into Dutch and were modified to 5-point scales to concur with the other scales used. Social presence affects social space and, thus, indirectly contributes to group atmosphere (social climate). Consequently, a moderate correlation between the aggregated scores of the items of the Group Atmosphere Scale and the items of our Social Presence Scale was expected. Because the Group Atmosphere Scale is very similar to Gunawardena's Social Presence Indicators, the correlation was expected to be of the same magnitude as the correlation between the aggregated scores of the items of the Social Presence Indicators and of the items of the Social Presence Scale.

\subsection{Refinement of the Raw Social Presence Scale}

The raw Social Presence Scale consisted of eight items, which were reduced to five items to derive a onedimensional social presence measure. First, two items were removed that did not accurately assess the psychological sensation associated with social presence. Principal Component Factor Analysis (no rotation) on the remaining six items revealed two factors with one item loaded equally strong on both factors. This item was removed. Table 9.1 depicts the refined Social Presence Scale. A second Principal Component Factor Analysis (no rotation) was performed on the five test items of the refined scale to obtain the factor loadings on the first and only factor. This factor explained $57.17 \%$ of the total variance.

\section{Results}

\subsection{Internal Consistency and Validity of the Scales}

The Social Presence Scale has a high internal consistency (Cronbach's alpha $=.81$ ). The content validity of the scales was established via a test face-validity. The items were developed based upon a search in the literature regarding social presence, telepresence, social interaction via CMC, group development and group dynamics, trust building, and creating sense of community. The authors of this article then assessed items.

\subsection{Pearson Bi-variate Correlations}

A Pearson bi-variate correlation (2-tailed) analysis was carried out on the aggregate scores of the test items of each measure involved (see Instrumentation). Table 2 depicts the correlations with respect to the Social Presence Scale.

Table 2 Pearson Bi-Variate Correlation Coefficients between the Social Presence Scale and the Other Scales (Text in parentheses reflects our predictions)

\begin{tabular}{|c|c|c|c|c|c|c|c|}
\hline \multirow[t]{4}{*}{ Measure } & \multirow{4}{*}{$\begin{array}{l}\text { Sociability } \\
\text { Scale }\end{array}$} & \multicolumn{2}{|c|}{ Social Space Scale } & \multirow{4}{*}{$\begin{array}{l}\text { Social } \\
\text { Presence } \\
\text { Indicators }\end{array}$} & \multirow{4}{*}{$\begin{array}{l}\text { GZ Social } \\
\text { Presence } \\
\text { Scale }\end{array}$} & \multirow{4}{*}{$\begin{array}{l}\text { Work Group } \\
\text { Cohesion } \\
\text { Index }\end{array}$} & \multirow{4}{*}{$\begin{array}{l}\text { Group } \\
\text { Atmosphere } \\
\text { Scale }\end{array}$} \\
\hline & & Positive & Negative & & & & \\
\hline & & Group & Group & & & & \\
\hline & & Behavior & Behavior & & & & \\
\hline Social & $.63 * *$ & $.53 * *$ & -.10 & $.66 * *$ & $.62 * *$ & $.44 * *$ & $.54 * *$ \\
\hline Prese & (modes & (moderate) & (?) & (modera & $(\bmod$ & (moder & $(\mathrm{mo}$ \\
\hline
\end{tabular}


As can be seen, the correlations vary between .44 and .66, which are at the low- and high end of the continuum that characterize moderate correlations (accounting for between $19 \%$ and $44 \%$ of the variance). The correlations between the aggregated scores of the Social Presence Scale and the Work Group Cohesion Index and the Group Atmosphere Scale are at the low end because social presence only indirectly affects social cohesiveness and group atmosphere through social interaction. The correlation between the aggregate scores of the Social Presence Scale and the Sociability Scale is at the high end because sociability directly affects social presence. The correlations between the aggregate scores of the Social Presence Indicators and of the GZ Social Presence Scale are also at the high-end because, ultimately, these measures were designed for assessing social presence.

\subsection{Factor Analysis of the Sociability, Social Presence, and Social Space Scales}

Finally, a Principal Component Factor Analysis (using Varimax rotation) was carried out on the 10 test items of the refined Sociability Scale, the 5 items of the Social Presence Scale, and the 20 items of the Social Space Scale to determine whether each of the measures assessed an isolated phenomenon (i.e., sociability, social presence and social space) or whether there was overlap. The extraction was, therefore, restricted to only four factors because the purpose of this analysis was not to reveal new factors but to determine the uniqueness of the scales with respect to each other. Because the Social Space Scale has two dimensions and both the Sociability Scale and the Social Presence scale only one, the restriction was set to four. The results of the factor analysis are presented in Table 3. From this table it can be seen that each of the three scales indeed measure an isolated phenomenon.

\section{Table 3}

Factor Analysis on the Scores of the Items of the Sociability Scale, Social Presence Scale, and the Social Space Scale

\begin{tabular}{|c|c|c|c|c|}
\hline \multirow{2}{*}{$\begin{array}{ll}\text { No. } & \text { Item } \\
\text { Item } & \end{array}$} & \multicolumn{4}{|c|}{ Factors } \\
\hline & Sociability & $\begin{array}{c}\text { Social } \\
\text { Presence }\end{array}$ & $\begin{array}{c}\text { Positive } \\
\text { Group } \\
\text { Behavior }\end{array}$ & $\begin{array}{c}\text { Negative } \\
\text { Group } \\
\text { Behavior }\end{array}$ \\
\hline
\end{tabular}

\begin{tabular}{lll}
\hline \multicolumn{1}{c}{ Sociability Scale } \\
1 & $\begin{array}{l}\text { This CSCL environment enables me to easily contact my team } \\
\text { mates }\end{array}$ & .74 \\
2 & $\begin{array}{l}\text { I do not feel lonely in this CSCL environment } \\
\text { This CSCL environment enables me to get a good impression } \\
\text { of my team mates }\end{array}$ & .76 \\
4 & $\begin{array}{l}\text { This CSCL environment allows spontaneous informal } \\
\text { conversations }\end{array}$ \\
5 & $\begin{array}{l}\text { This CSCL environment enables us to develop into a well } \\
\text { performing team }\end{array}$ \\
6 & $\begin{array}{l}\text { This CSCL environment enables me to develop good work } \\
\text { relationships with my team mates }\end{array}$ \\
7 & $\begin{array}{l}\text { This CSCL environment enables me to identify myself with } \\
\text { the team }\end{array}$ \\
8 & $\begin{array}{l}\text { I feel comfortable with this CSCL environment } \\
\text { This CSCL environment allows for non task-related }\end{array}$ \\
9 & $\begin{array}{l}\text { conversations } \\
\text { This CSCL environment enables me to make close friendships }\end{array}$ \\
10 & $\begin{array}{l}.70 \\
\text { with my team mates }\end{array}$ \\
\end{tabular}

Social Presence Scale

1 When I have real-time conversations in this CSCL environment, I have my communication partner in my mind's eye

2 When I have asynchronous conversations in this CSCL environment, I also have my communication partner in my mind's eye 
environment, I feel that I deal with very real persons and not with abstract anonymous persons

4 When I have asynchronous conversations in this CSCL

environment, I also feel that I deal with very real persons and not with abstract anonymous persons

5 Real-time conversations in this CSCL environment can hardly be distinguished from face-to-face conversations

Positive Group Behavior

1 Group members felt free to criticize the ideas, statements, and/or opinions of others

2 We reached a good understanding on how we had to function

3 Group members ensured that we kept in touch with each other

7 The group conducted open and lively conversations and/or

\section{discussions}

8 Group members took the initiative to get in touch with others

9 Group members spontaneously started conversations with others

10 Group members asked others how the work was going

11 Group members felt that they were attacked personally when

their ideas, statements and/or opinions were criticizeda

12 Group members were suspicious of othersa

13 Group members grew to dislike othersa

14 I did the lion's share of the worka

15 Group members obstructed the progress of the worka

16 Group members were unreasonablea

17 Group members disagreed amongst each othera

19 Group members gossiped about each othera

20 Group members did not take others seriouslya

a These items were reverse coded for analysis.

\section{Discussion}

It is clear from the results that social presence is a unique construct and that existing instruments for determining its degree of presence are inadequate. The results of this study, both empirical and nomological, unequivocally show that the instrument designed here, if nothing else, is an important step in the right direction.

The validation of the social presence measure, however, does have some weak points. First, the number of cases was 79. A general rule of the thumb is that there must be at least five to ten cases per item when performing a factor analysis. The raw Social Presence Scale initially contained eight items, implying that we needed between 40 and 80 cases. This condition was fulfilled. However, the factor analysis involving the three measures actually required between 175 and 350 cases, and this condition was not fulfilled. Second, three samples were collapsed in order to obtain the 79 cases and not one homogenous sample. A mitigating circumstance here is that earlier internal research at the OUNL with respect to student characteristics shows that the student populations for these courses do not differ. Third, the same cases for the factor analysis were used as on the test items of the refined Sociability Scale, the Social Presence Scale, and the Social Space Scale. Due to this, the result (Table 3) might benefit from the chance characteristic of the 79 cases from which the Social Presence Scale (and the two other measures) was derived.

In other words, though the results are very promising, the findings only suggest that the Social Presence Scale has potential to be useful as measures for measuring social presence. More research is needed to corroborate the findings here. 


\section{References}

Archer, W, Garrison, D. R., Anderson, T., Rourke, L. (2001). A framework for analyzing critical thinking in computer conferences. In P. Dillenbourg, A. Eurlings, \& K. Hakkarainen (Eds.), Proceedings of the 1st European conference on computer-supported collaborative learning: European perspectives on computer-supported collaborative learning (pp. 59-66). Maastricht: Maastricht McLuhan Institute.

Andersen, J. (1979). Teacher immediacy as a predictor of teaching effectiveness. In D. Niimo (Ed.), Communication yearbook 3 (pp. $543-$ 559). New Brunswick, NJ: Transaction Books.

Argyle, M., \& Dean, J. (1965). Eye contact, distance and affiliation. Sociometry, 28, 289-304.

Cobb, S. C. (2009). Social presence and online learning: A current view from a research perspective. Journal of Interactive Online Learning, $8(3), 241-254$.

Fiedler, F. E. (1962). Leader attitudes, group climate, and group creativity. Journal of Abnormal and Social Psychology, 65, 308-318.

Fiedler, F. E. (1967). A theory of leadership effectiveness. New York: McGraw-Hill.

Fulk, J., Schmitz, J., \& Steinfield, C. W. (1990). A social influence model of technology use. In J. Fulk \& C. W. Steinfield (Eds.), Organizations and Communication Technology (pp. 117-140). London and Newbury Park, CA: Sage.

Garramone, G. M., Harris, A. C., \& Anderson, R. (1986). Uses of political computer bulletin boards. Journal of Broadcasting \& Electronic Media, 30, 325-339.

Garrison, D. R. (1993). A cognitive constructivist view of distance education: An analysis of teaching-learning assumptions. Distance Education, 14, 199-211.

Garrison, D. R. (1997a). Computer conferencing: The post-industrial age of distance education. Open Learning, 12 (2), 3-11.

Garrison, D. R. (June, 1997b). Computer conferencing in distance education: Cognitive and social presence issues. In Proceedings of the 18th World conference of the International council for distance education (ICDE): The new learning environment: A global perspective. Pennsylvania: Pennsylvania State University.

Garrison, D. R. \& Anderson, T. (2003). E-learning in the 21st century. London: Routledge Falmer.

Garrison, D. R., Anderson, T., \& Archer, W. (2000). Critical thinking in a text-based environment: Computer conferencing in higher education. Internet and Higher Education, 11(2), 1-14.

Gunawardena, C. N. (1995). Social presence theory and implications for interaction and collaborative learning in computer conferences. International Journal of Educational Telecommunications, 1(2/3), 147-166.

Gunawardena, C. N., \& Zittle, F. (1997). Social presence as a predictor of satisfaction within a computer mediated conferencing environment. American Journal of Distance Education, 11(3), 8-25.

Hills, A. (2005). Social presence and communication quality in videoconferencing. Unpublished bachelor dissertation, University of Otago, New Zealand

Hiltz, S. R. (1994). The Virtual Classroom: Learning without limits via computer networks. Norwood, NJ: Ablex Publishing Corporation.

Jacques, D. (1992). Learning in groups (2nd ed.). London: Kogan Page.

Jessup, L. M., Connolly, T., \& Tansik, D. A. (1990). Toward a theory of automated group work: The deindividuating effects of anonymity. Small Group Research, 21, 333-348.

Johnson, R. T., Johnson, D. W., \& Stanne, M. B. (1985). Effects of cooperative, competitive, and individualistic goal structures on computerassisted instruction. Journal of Educational Psychology, 77, 668-677.

Kearsley, G. (1995). The nature and value of interaction in distance learning. (ACSDE Research Monograph No. 12, pp. 83-92). University Park, PA: Pennsylvania State University, American Center for the Study of Distance Education.

Koh, J., Kim, Y.-G., Butler, B., Bock, G.-W. (2007). Encouraging participation in virtual communities. Communications of the ACM. 50(2), 69-73.

Kreijns, K., Kirschner, P. A., \& Jochems, W. (2002). The sociability of computer-supported collaborative learning environments. Journal of Education Technology \& Society, 5(1), 8-22.

Kreijns, K., Kirschner, P. A., \& Jochems, W. (2003). Identifying the pitfalls for social interaction in computer-supported collaborative learning environments: A review of the research. Computers in Human Behavior, 19, 335-353.

Kreijns, K., Kirschner, P. A., Jochems, W., \& Van Buuren, H. (2004). Measuring perceived quality of social space in distributed learning groups. Computers in Human Behavior, 20, 607-632.

Kreijns, K., Kirschner, P. A., Jochems, W., \& Van Buuren (2007). Measuring Perceived Sociability of Computer-Supported Collaborative Learning Environments. Computers \& Education, 49, 176-192.

Lin, G.-Y. (2004, October 19-23). Social Presence Questionnaire of Online Collaborative Learning: Development and Validity. Paper presented at the 27th Association for Educational Communications and Technology (AECT) Covention. Chicago, IL.

Liu, S. Y., Gomez, J., \& Yen, C-J., (2009). Community college online course retention and final grade: Predictablility of social presence. Journal of Interactive Online Learning, 8(2), 165-182.

Lombard, M. \& Ditton, T. (1997). At the heart of it all: The concept of presence. Journal of Computer-Mediated Communication, 3(2). Retrieved January 29, 2003, from http://www.ascusc.org/jcmc/vol3/issue2/lombard.html.

Lowenthal, P. R. (2010). The evolution and influence of social presence theory on online learning. In T. T. Kidd (Ed.), Online Education and Adult Learning: New Frontiers for Teaching Practices (pp. 124-134). Hershey, PA: IGI Global.

Osgood, C. E., Suci, G. J., \& Tannenbaum, P. H. (1957). The measure of meaning. Urbana, IL: University of Illinois Press.

Price, J. L., \& Mueller, C. W. (1986). Handbook of organizational measurement. Marshfield, MA: Pitman Publishing.

Rice, R. E. (1993). Media appropriateness: Using social presence theory to compare traditional and new media. Human Communication Research, 19, 451-484.

Rourke, L., \& Anderson, T. (2002) Exploring social communication in asynchronous, text-based computer conferencing. Journal of Interactive Learning Research, 13, 259-275.

Rourke, L., Anderson, T., Garrison, D. R., \& Archer, W. (1999). Assessing social presence in asynchronous, text-based computer conferences. Journal of Distance Education, 14(3), 51-70.

Shen, K. N., Khalifa, M., \& Yu, A Y. (2006, August 4-6). Supporting social interaction in virtual communities: Role of social presence. Paper presented at the 12th Americas conference on Information systems. Acapulco, Mexico.

Short, J., Williams, E., \& Christie, B. (1976). The social psychology of telecommunications. London: John Wiley \& Sons, Ltd.

Slavin, R. (1995). Cooperative learning: Theory, research, and practice (2nd ed.). Needham Heights, MA: Ally and Bacon.

Soller, A. L., \& Lesgold, A., Linton, F., Goodman, B. (1999). What makes peer interaction effective? Modeling effective communication in an intelligent CSCL. In Proceedings of the 1999 AAAI fall symposium: Psychological models of communication in collaborative systems (pp. 116-123). Cape-Cod, MA.

Spears, R., Postmes, T., Wolbert, A., Lea, M., \& Rogers, P. (2000). Social psychological influence of ICT on society and their policy implications [Electronic version]. Amsterdam: Infodrome. 
Stacey, E. (2000). Quality online participation : establishing social presence. In Research in distance education 5: Revised papers from the 5th Research in distance education conference (pp. 138-153). Melbourne, Vict. :Deakin University.

Stacey, E. (2002). Social presence online: networking learners at a distance. Education and Information Technologies, 7, $287-294$.

Steinfield, C. (1986). Computer-mediated communication in an organizational setting: Explaining task-related and socioemotional uses. In M. L. McLaughlin (Ed.), Communication Yearbook 9 (pp. 777-804). Newbury Park, CA: Sage

Swan, K. (2002). Building learning communities in online courses: The importance of interaction. Education, Communication and Information, 2(1), 23-50.

Towell, J., \& Towell, E. (1997). Presence in text-based networked virtual environments or “MUDS.” Presence. Teleoperators and Virtual Environments 6, 590-595.

Tu, C. H. (1997). Using CMC to increase the social presence of Chinese students. Paper presented at the Association for Educational Communication and Technology (AECT) annual conference, Albuquerque, NM.

Tu, C. H. (2000a). On-line learning migration: From social learning theory to social presence theory in a CMC environment. Journal of Network and Computer Applications, 23(1), 27-37.

Tu, C. H. (2000b). Critical examination of factors affecting interaction on CMC. Journal of Network and Computer Applications, 23(1), 3958.

Tu, C. H. (2001). How Chinese perceive social presence: An examination of an online learning environment. Educational Media International, 38(1), 45-60.

Tu, C. H. (2002a). The relationship between social presence and online privacy. Internet and Higher Education, 5, 293-318.

Tu, C. H. (2002b). The measurement of social presence in an online learning environment. International Journal on E-learning, 1(2), $34-45$.

Tu, C, H. (2002c). The impacts of text-based CMC on online social presence. The Journal of Interactive Online Learning, 1(2), 1-24.

Tu, C. H., \& McIsaac, M. (2002). An examination of social presence to increase interaction in online classes. American Journal of Distance Education, 16(3), 131-150

Walther, J. B. (1992). Interpersonal effects in computer-mediated interaction: A relational perspective. Communication Research, 19(1), 5290

Walther, J. B., \& Burgoon, J. K. (1992). Relational communication in computer-mediated interaction. Human Communication Research, 19(1), 50-88.

Wiener, M., \& Mehrabian, A. (1968). Language within language: Immediacy, a channel in verbal communication. New York: AppletonCentury-Crofts.

Witmer, D. F. (1997). Risky business: why people feel safe in sexually explicit on-line communication. Journal of Computer Mediated Communication, 2(4). Retrieved January 29, 2005, from http://www.ascusc.org/jcmc/vol2/issue4/witmer2.html

Yoo, Y., \& Alavi, M. (2001). Media and group cohesion: Relative influences on social presence, task participation, and group cohesiveness, MIS Quarterly, 25, 371-390. 